\title{
Morphological, Histochemical and Biochemical Features of Cultivated Rhodiola rosea (Altai Mountains Ecotype)
}

\author{
A. A. Erst ${ }^{a}$, A. A. Petruk ${ }^{a}$, L. N. Zibareva ${ }^{b, *}$, and A. S. Erst ${ }^{a, b}$ \\ ${ }^{a}$ Central Siberian Botanical Garden, Siberian Branch, Russian Academy of Sciences, Novosibirsk, 630090 Russia \\ ${ }^{b}$ National Research Tomsk State University, Tomsk, 634050 Russia \\ *e-mail: zibareva.lara@yandex.ru \\ Received August 1, 2021; revised August 17, 2021; accepted August 19, 2021
}

\begin{abstract}
The study analyzed the content and localization of phenolic compounds, in particular phenylpropanoids, of Rodiola rosea plants of Altai Mountains ecotype during the introduction period of 2-4 years in the conditions of the forest-steppe zone of Western Siberia. The plant material for the introduction experiment was obtained by in vitro method. HPLC was used to identify 11 phenolic compounds, including gallic acid, rosarin, rosavin, rosin, cinnamyl alcohol, rhodiosin, rhodionin, and kaempferol. The highest content of phenylpropenoids was found in rhizomes of the 4-year-old $R$. rosea plants: $1.02 \%$ rosarin, $2.64 \%$ rosavin, $1.05 \%$ rosin, $3.39 \%$ cinnamyl alcohol. Analysis of the phenylpropanoid profile showed that the predominant component in all the studied samples was cinnamyl alcohol (up to 58\%). Histochemical studies identified phenolic substances in the rhizomes and roots of $R$. rosea, which are localized in parenchymal and vascular tissues. It was revealed that the total rhizome biomass exceeded that of the root, and by the $4^{\text {th }}$ year of introduction, it was approximately 2 -fold greater in dry weight. The study showed high biosynthetic potential and biological productivity of the studied $R$. rosea ecotype upon introduction.
\end{abstract}

Keywords: roseroot, cultivation, in vitro, ecotype, rosavin, cinnamyl alcohol, histochemistry

DOI: $10.1134 / \mathrm{S} 1995425521060135$

\section{INTRODUCTION}

One of the valuable endangered medicinal plant species is Rhodiola rosea L., family Crassulaceae. Preparations from $R$. rosea rhizomes and roots are used as adaptogens and anti-stress agents, and are also widely used in the cosmetic industry and as a component of "functional foods" (Lamadrid et al., 2019; European Commission, 2020; Panossian and Brendler, 2020; Brinckmann et al., 2021). The global demand for this drug category has increased many fold due to an unfavorable sanitary and epidemiological situation in the world caused by the new coronavirus infection (COVID-19). Wide use of these drugs causes quality concerns due to limited resources and insufficient control, which leads to replacement of $R$. rosea raw materials with other Rhodiola species (Peschel et al., 2016). The researchers report that the content of rosavin or cinnamyl alcohol (CA) glycosides allows a more reliable standardization of the authenticity and quality of medicinal $R$. rosea raw materials as compared with salidroside (a generally accepted marker) (Altantsetseg et al., 2007; Kurkin, 2013; Panossian et al., 2010). In addition, the results obtained by Kędzia et al. (2006) indicate that salidroside does not affect the immunostimulatory and tranquilizing activity of $R$. rosea extracts. In this regard, in recent years, researchers have been paying more and more attention to phenylpropenoid content in $R$. rosea. For example, the USP monograph requires $0.3 \%$ dry weight of phenylpropenoid glycosides (rosarin, rosavin, and rosin) in terms of rosavin (in addition to $0.08 \%$ salidroside) (USP, 2015); according to the Russia State Pharmacopoeia, the amount of CA glycosides in terms of rosavin must be not less than $1 \%$, and not less than $0.8 \%$ of salidroside (Gosudarstvennaya farmakopeya..., 2015).

Despite a great interest in $R$. rosea and extensive research in phytochemistry, one potential area-plant biotechnology-remains less studied and less used for this species compared to other medicinal plants (Tasheva and Kosturkova, 2012). Earlier, we reported on the features of in vitro cultivation of $R$. rosea from various populations growing on the territory of Russia (Erst and Yakubov, 2019), and in particular from the population of Altai Mountains (Erst et al., 2018). Under in vitro model conditions, we have shown significant differences in growth and development parameters of $R$. rosea depending on the population origin. The concept of the geographic or ecological race states that continuous selection pressure in a particular habitat causes certain changes in the genotype of individuals from the local population, which are manifested in their phenotype (Banaev, 2009). The research- 
ers note that different $R$. rosea ecotypes significantly differ in the content of glycosides in plants (Zakhozhiy, 2006). Natural reserves of $R$. rosea are depleting, therefore, the development of in vitro cultivation technologies for most promising samples, as well as assessment of their biosynthetic potential and biological productivity upon introduction, are extremely urgent.

The study aims to analyze the content and localization of phenolic compounds, in particular phenylpropenoids, in $R$. rosea Altai Mountains ecotype plants upon introduction in the forest-steppe zone of Western Siberia.

\section{MATERIAL AND METHODS}

\subsection{Plant Material}

The initial test material was seeds of the $R$. rosea plant from the Altai Republic (Russia), growing on the southern slopes of the Iolog ridge, Karakol lakes. Altitude of 1800-2000 m a.s.l. The classification by E.F. Kim (1977) refers the samples to the second $R$. rosea ecotype-moderately humid habitats with moderate soil moisture (44-50\%).

\subsection{Ecological and Geographical Characteristics of the Cultivation Site}

The introduction site is located on the territory of the Central Siberian Botanical Garden (CSBS) of the Siberian Branch Of the Russian Academy of Sciences (SB RAS), located on the right bank of the Novosibirsk reservoir, $25 \mathrm{~km}$ from the center of Novosibirsk (Russia). Geomorphologically, the CSBG territory occupies the second and third terraces above the floodplain of the $\mathrm{Ob}$ River composed of ancient alluvial sandy and sandy loam deposits. The average height of the terraces is $150-200 \mathrm{~m}$ a.s.l. The climate is sharply continental with significant fluctuations in seasonal and daily temperatures. Winters are long and harsh, and summers are short and hot. A frostfree period typically does not exceed 150 days, and the period with temperatures above $10^{\circ} \mathrm{C}$ lasts $120-$ 140 days. The sum of active temperatures above $5^{\circ} \mathrm{C}$ in August attains $1400-1600^{\circ} \mathrm{C}$, and that above $10^{\circ} \mathrm{C}$ is about $800^{\circ} \mathrm{C}$. In May, the sum of temperatures above $10^{\circ} \mathrm{C}$ rarely exceeds $100^{\circ} \mathrm{C}$, and it is typically significantly lower $\left(70-80^{\circ} \mathrm{C}\right)$. Spring is long with possible return frosts in May-June. The first autumn frosts occur in the second or third decades of September. Snow cover averages about $40 \mathrm{~cm}$. Soil in open areas can freeze to a depth of $2 \mathrm{~m}$ or more. The annual precipitation is about $400 \mathrm{~mm}$, of which about $70 \%$ falls in the frost-free period, and about $40 \%(150-170 \mathrm{~mm})$ in summer. There is a deficiency of atmospheric and soil moisture during an active vegetation period of plants. Soils are classified as low and medium humus. The reaction of the soil environment is acidic or slightly acidic. For soddy-podzolic soils, the $\mathrm{pH}$ level varies within 5.5-6.9, in gray forest soils in the leached stratum, it is 5.5-6.0, and in the carbonate horizon, the $\mathrm{pH}$ is 7.8-7.9 (Rastitel'noe mnogoobrazie..., 2014).

\subsection{Propagation, Cultivation, Harvest, and Drying}

2.3.1. In vitro propagation. In vitro cultivation of $R$. rosea was fulfilled on the basis of the Laboratory of Biotechnology, CSBG SB RAS (Novosibirsk) according to the previously developed method (Erst et al., 2018; Erst and Yakubov, 2019) with regard to recommendations for in vitro reproduction of $R$. rosea of the second ecotype (Ishmuratova, 1998). The seeds of $R$. rosea were used as material for in vitro introduction.

2.3.2. Adaptation to ex vitro conditions and outdoor cultivation. In vitro regenerated plants were adapted to non-sterile conditions in cassettes; the substrate was perlite : peat $(1: 2)$. The substrate was spilled with fungicide solution (Baktofit, Russia) at a rate of $10 \mathrm{~g}$ per $5 \mathrm{~L}$ of water or with weak solution of potassium permanganate to prevent and control fungal and bacterial plant diseases. For the first 5 days of adaptation, the plants were covered with a transparent film to increase air humidity. The plants were grown indoors at $24 \pm$ $2^{\circ} \mathrm{C}$, illumination of $2-3 \mathrm{klx}$, photoperiod of $16 / 8 \mathrm{~h}$ light/dark for 30 days. After a month, the plants were transplanted into $10 \times 10 \times 11 \mathrm{~cm}$ containers by transferring them into the soil mixture, which consisted of a peat nutrient substrate and sand in a ratio of $2: 1$, and grown for 7 months in a greenhouse. The plants from the containers were then transferred to the nursery and grown for another 2 years. The 3 -year-old plants were planted in the introduction site in ridges with spacing between plants of $20-25 \mathrm{~cm}$. To protect against weeds, buds were covered with black polythene. No additional fertilizers or other cultivation measures, other than irrigation, were applied.

2.3.3. Harvest and drying. The crop was harvested in October 2018 (2nd year, nursery), 2019 (3rd year, introduction site) and 2020 (4th year, introduction site). Rhizomes and roots were shaken off the soil and washed; then roots were separated from rhizomes and cut into pieces (maximum thickness of $1 \mathrm{~cm}$ ). Fresh weight (FW) and dry weight (DW) of roots and rhizomes were recorded for each plant before and after drying via warm air ventilation at $45^{\circ} \mathrm{C}$ for 5 days. Dry samples were stored in paper bags under dark and dry conditions at $10-25^{\circ} \mathrm{C}$.

\subsection{Morpho-Anatomical and Histochemical Analysis}

Parts of rhizomes and roots of 4-year-old $R$. rosea plants were fixed in formalin, acetic acid, $70 \%$ ethanol, $7: 7: 100 \mathrm{v} / \mathrm{v} / \mathrm{v}$ (FAA70) for 4 days and then stored at $70 \%(\mathrm{v} / \mathrm{v})$ ethanol. For fluorescent microscopy, fresh parts of plants were used.

2.4.1. Microscopy procedures. For anatomical characterization, FAA70 fixed parts of $R$. rosea were sectioned $(25-35 \mu \mathrm{m})$ by microtome MICROM HM 430 (Thermo Fisher Scientific, Germany) with fast freez- 
ing unit KS 34 S (Thermo Fisher Scientific, Germany). For light microscopy, sections were analyzed by Carl Zeiss Axioscope Al microscope equipped with digital camera Axiocam 506 color and software ZEN 2012 (blue edition) (Carl Zeiss Ltd, Herts, UK), and Carl Zeiss Primo Star iLED equipped with filter system $(470 \mathrm{~nm})$, digital camera AxioCam MRc 5 and software AxioVision 4.8 (Carl Zeiss Ltd, Herts, UK).

2.4.2. Histochemical tests. Cross sections were investigated using the following histochemical tests: ferric chloride (Johansen, 1940) reagent to detect phenolic compounds; Lugol's solution to detect starch (Johansen, 1940); Wiesner reaction to demonstrate lignin (Wiesner, 1878).

For fluorescent microscopy, fresh sections were processed using a $2 \%(\mathrm{w} / \mathrm{v})$ solution of safranin to detect starch, $2 \mathrm{~min}$, and $1 \%(\mathrm{w} / \mathrm{v})$ acridine orange to detect lignin, $2 \mathrm{~min}$, inducing yellow and green fluorescence at $470 \mathrm{~nm}$, respectively. For autofluorescence examination, the sections were directly viewed under LED light at $470 \mathrm{~nm}$.

\subsection{Biochemical Analysis}

2.5.1. Extraction. The dry raw material was crushed to a particle size of $2 \mathrm{~mm}$, mixed and an average sample was taken. Double extraction was performed to extract phenolic compounds. An exact weighed portion $(0.5 \mathrm{~g})$ of the crushed material was extracted with $30 \mathrm{ml}$ of aqueous $50 \%$ ethanol during the day, and then $20 \mathrm{~mL}$ of $70 \%$ ethanol for $50 \mathrm{~min}$ in a water bath. A filter cake was washed with $5 \mathrm{ml}$ of $70 \%$ ethanol. The combined extract was concentrated to $20 \mathrm{~mL}$. To remove impurities, $1 \mathrm{~mL}$ of the extract was diluted with double-distilled water to $5 \mathrm{ml}$ and passed through a Diapak C16 (ZAO BioKhimMak, Russia) concentrating cartridge.

2.5.2. HPLC analysis. The component composition of the phenolic complex of the samples was investigated by high performance liquid chromatography (HPLC) using an Agilent 1200 liquid chromatograph (Agilent Technologies, USA) equipped with a diode array detector, Zorbax SB-C18 column $(4.6 \times 150 \mathrm{~mm}$, with sorbent grain size $5 \mu \mathrm{M}$, Agilent Technologies, USA). In the mobile phase, the methanol content in the aqueous solution of phosphoric acid $(0.1 \%)$ varied from 50 to $52 \%$ within $56 \mathrm{~min}$. The flow rate of the eluent was $1 \mathrm{ml} / \mathrm{min}$, the column temperature was $26^{\circ} \mathrm{C}$, and the volume of the injected sample was $10 \mu 1$. Detection was carried out at $\lambda=220,250,270,290$, 360 , and $370 \mathrm{~nm}$. The content of substances was calculated during detection at $255 \mathrm{~nm}$. Methyl alcohol (extra pure grade), orthophosphoric acid (extra pure grade), and bidistilled water were used to prepare mobile phases. Samples from Aobious (USA) and Sigma Aldrich (Germany) were used for identification. Standard solutions were prepared at a concentration of $10 \mu \mathrm{g} / \mathrm{ml}$ in ethyl alcohol. The retention time of
Table 1. Yield (FW), fresh-dry weight ratio and rhizomeroot ratio (DW) of 2- to 4-year-old samples of $R$. rosea cultivated in CSBG (Novosibirsk, Russia)

\begin{tabular}{c|c|c|c}
\hline & Total FW, g & $\begin{array}{c}\text { FW-DW ratio } \\
(x: 1)\end{array}$ & $\begin{array}{c}\text { Rhizome/root } \\
\text { ratio DW }(1: x)\end{array}$ \\
\hline Year 2 & $10.26 \pm 1.76$ & $3.54 \pm 0.31$ & $0.71 \pm 0.20$ \\
Year 3 & $18.15 \pm 3.92$ & $4.32 \pm 0.37$ & $0.75 \pm 0.25$ \\
Year 4 & $117.74 \pm 23.00$ & $7.75 \pm 0.93$ & $0.58 \pm 0.15$ \\
\hline
\end{tabular}

FW-fresh weight, DW-dry weight. Data are presented as mean values with confidence intervals $(p \leq 0.05)$.

the peaks of compounds in the chromatograms of the analyzed samples and their UV spectra was compared with these of the standard samples. Quantitative determination of individual components in plant samples was carried by external standard method (\% of the weight of air-dry raw materials).

In the study, we summarized the total amount of rosavins $(\mathrm{ROS}=$ rosarian + rosavin + rosin $)$ and the total amount of phenylpropanoids $(\mathrm{PP}=\mathrm{ROS}+\mathrm{CA})$. The ratio parameters were calculated for some relative comparisons: rosarin-rosavin-rosin-CA ratio (with rosarin set as 1) and ROS-CA ratio (with CA set as 1).

\subsection{Experimental Design and Data Analysis}

Statistical processing of the results and analysis of the data were performed using Microsoft Excel 7.0. All experiments were performed in two replications with 10 plants, rhizomes, roots in each replicate. Data are presented as mean values and confidence intervals $(p \leq 0.05)$.

\section{RESULTS}

\subsection{Increase in Biomass of Underground Parts}

Dynamics of an increase in the rhizome and root biomass is shown in Fig. 1 and Table 1. The total rhizome biomass exceeded that of the root, and after 4 years of cultivation, it exhibited a 2 -fold increase in dry weight (rhizome-root ratio of $1: 0.58$ ). The relationship between the age and the water content in roots and rhizomes is evidenced by the loss of moisture during drying in the FW-DW ratio of $3.5: 1$ for the 3 -year-old plants and $7.8: 1$ for the 4-year-old plants. It should be noted that rhizomes of the 4-year-old plants are easily divided into separate segments (particulars) and can be used as mother plants for successful plantation establishment (Fig. 1).

\subsection{Morpho-Anatomical and Histochemical Analysis}

A transverse section of the root and rhizome shows a layered periderm (Fig. 2). At the root, its thickness attains $100-120 \mu \mathrm{m}(6-7$ layers), and at the rhizome, it amounts to $320-470 \mu \mathrm{m}$ (24-26 layers). The struc- 


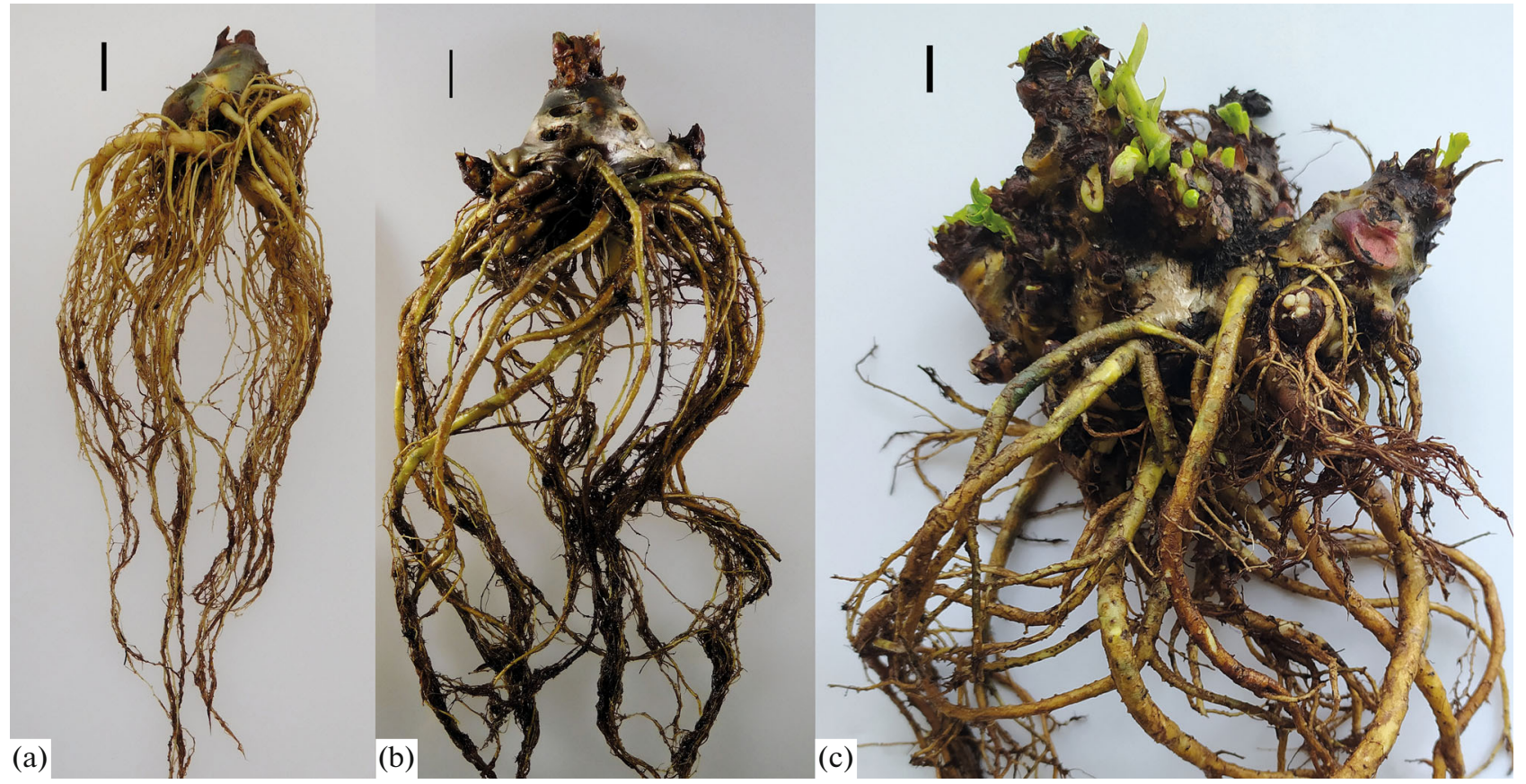

Fig. 1. Samples of R. rosea, (a) 2-, (b) 3-, and (c) 4-year-old, cultivated in CSBG (Novosibirsk, Russia). Bar: $1 \mathrm{~cm}$.

ture of the rhizome is of bundle type. The vascular bundles are open, collateral, fusiform, arranged in a ring, with phloem oriented to the rhizome periphery and xylem oriented to the center. The parenchyma of the root and rhizome consists of large cells filled with starch. Starch grains are simple, round or oval, 5-20 $\mu \mathrm{m}$ in diameter. Areas covered with a cork layer can be seen in the thickness of the rhizome (Fig. 2).

Histochemical tests revealed tissues stained as a result of the interaction between reagents and the detected components, which causes their specific binding. The parenchyma of the root and rhizome showed the following positive reactions: Lugol reaction for starch (Figs. 2c, 2i) - purple color, ferric chloride reaction for phenolic compounds (Figs. 2b, 2h) - brown color and Wiesner reaction for lignin (Figs. 2j, 2k) - red color. Phenolic compounds are distributed throughout the entire thickness of the root and rhizome in parenchymal cells and cells of the vascular system. In the cork layer, the test for phenolic compounds was negative. No phenolic compounds were identified in the cork layer. The presence of the starch and lignin was also confirmed by fluorescence microscopy. Safranin gave the yellow fluorescence to starch grains in parenchymal cells (Figs. 2f, 21). Xylem elements and periderm were identified with by acridine orange by green fluorescence (Figs. 2d, 2e).

\subsection{Biochemical Analysis}

3.3.1. Qualitative composition and content of phenolic compounds of $R$. rosea herb, rhizomes, and roots. HPLC for isolating a complex set of phenolic com- pounds was used to detect 11 components in the samples of $R$. rosea plants grown on the territory of the CSBG (Table 2).

A quantitative content of each compound from the collections of different years varies from 0.02 to $3.39 \%$. The highest content of gallic acid $(0.28 \%)$ was found in the aerial parts of the 4-year-old plants. In general, the content of this phenolcarboxylic acid in other samples varied insignificantly-from 0.8 to $0.13 \%$; in rhizomes of the 4-year-old plants, it amounted to $0.19 \%$.

Compound 2 varied from 0.05 to $0.08 \%$, or was not identified, except for roots of the 2- and 3-year-old plants, where its content attained $0.20-0.23 \%$. Compounds 3 and 4 showed the highest content in the aerial parts of plants (0.61 and $1.01 \%$, respectively), whereas in the underground parts they either were absent or exhibited insignificant values $(0.02-0.09 \%)$. Only rhizomes of the 4-year-old plants showed an increased amount of this compound (up to $0.36 \%$ ).

Compounds 5-8 were identified as cinnamyl alcohol and its derivatives, phenylpropanoids: rosarin, rosavin and rosin, with maxima at $253 \mathrm{~nm}$. The highest content was found in rhizomes (Fig. 3A). We did not reveal these compounds in the aerial parts of $R$. rosea.

Compounds 9 and 10, flavonoids rhodiosin and rhodionin, with maxima at $277,333,385 \mathrm{~nm}$, were found in almost all the samples, except for the aerial part. The content of rhodiosin ranged from 0.04 to $0.48 \%$, and that of rhodionin varied from 0.11 to $1.02 \%$. The largest amount of these compounds was found in roots of the 2-year-old plants (Fig. 3b). 


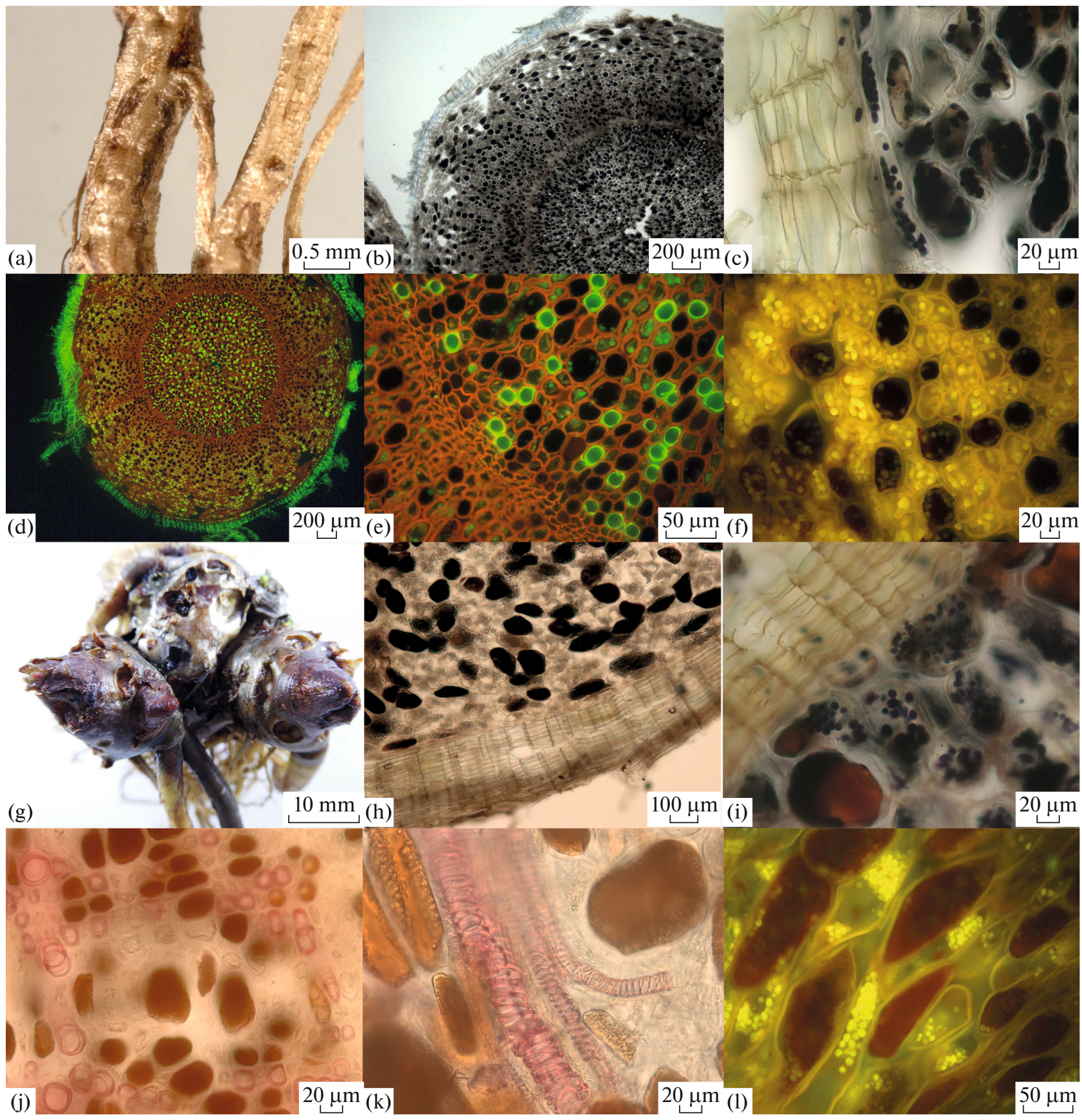

Fig. 2. Cross sections of root $(\mathrm{a}-\mathrm{f})$ and rhizome $(\mathrm{j}-1)$ of $R$. rosea treated with histochemical reagents, using light microscopy: (a) root; (g) rhizome; (b, h) ferric chloride for phenolic compounds; (c, i) Lugol's solution for starch; (d, e) acridine orange for lignin under UV (green fluorescence); ( $f, 1)$ safranin for starch under UV (yellow fluorescence); (j) Wiesner reaction for lignin;

(k) fragments of spiral vessels (Wiesner reaction for lignin).

An insignificant amount of the flavonoid kaempferol (flavonol) was observed in all the samples (more than $0.05 \%$ ), with its highest content in roots of the 3 -year-old plants $(0.12 \%)$.

No other compounds, except for compounds 1-4, were found in the aerial part. However, unlike other samples, the aerial part contained unidentified phenolic compounds with retention times of 11.8 and $13.4 \mathrm{~min}$ absorption maxima of 216 and $280 \mathrm{~nm}$, with a predominant peak area in the chromatogram (Fig. 3c).

3.3.2. Phenylpropanoid content in $R$. rosea rhizomes and roots with regard to age. The content of both ROS and CA was observed to increase in roots and rhizomes of the 4-year-old plants (Table 3). The highest content was recorded for both of them: $1.02 \%$ rosarin, $2.64 \%$ rosavin, $1.05 \%$ rosin, and $3.39 \%$ cinnamyl alcohol. 
Table 2. Qualitative composition and content of phenolic compounds of $R$. rosea herb, rhizomes, and roots (\%)

\begin{tabular}{l|c|c|c|c|c|c|c|c|c|c|c}
\hline \multirow{2}{*}{ Sample, date of collection } & \multicolumn{9}{c}{ Phenolic compounds, \% } \\
\cline { 2 - 10 } & $\mathbf{1}$ & $\mathbf{2}$ & $\mathbf{3}$ & $\mathbf{4}$ & $\mathbf{5}$ & $\mathbf{6}$ & $\mathbf{7}$ & $\mathbf{8}$ & $\mathbf{9}$ & $\mathbf{1 0}$ & $\mathbf{1 1}$ \\
\hline Roots, October 16, 2018 (year 2) & 0.09 & 0.20 & 0.03 & 0.07 & 0.09 & 0.25 & 0.13 & 0.27 & 0.48 & 1.02 & 0.06 \\
Rhizomes, October 16, 2018 (year 2) & 0.11 & - & 0.03 & 0.04 & 0.67 & 1.69 & 0.33 & 2.77 & 0.20 & 0.54 & 0.05 \\
Roots, October 25, 2019 (year 3) & 0.08 & 0.23 & 0.02 & - & 0.03 & 0.06 & 0.06 & 0.20 & 0.12 & 0.33 & 0.12 \\
Rhizomes, October 25, 2019 (year 3) & 0.13 & 0.07 & 0.06 & 0.05 & 0.60 & 1.00 & 0.41 & 2.52 & 0.19 & 0.75 & 0.05 \\
Roots, October 7, 2020 (year 4) & 0.13 & 0.05 & 0.07 & - & 0.19 & 0.37 & 0.24 & 0.78 & 0.04 & 0.11 & - \\
Rhizomes, October 7, 2020 (year 4) & 0.19 & 0.08 & 0.09 & 0.36 & 1.02 & 2.64 & 1.05 & 3.39 & 0.13 & 0.46 & - \\
Herb, October 7, 2020 (year 4) & 0.28 & 0.08 & 0.61 & 1.01 & - & - & - & - & - & - & - \\
Roots, September 22, 2020 (year 4) & 0.12 & 0.05 & 0.09 & - & 0.09 & 0.13 & 0.08 & 0.53 & 0.05 & 0.11 & - \\
Periderm of rhizomes, September 22, 2020 & 0.08 & 0.05 & 0.04 & - & 0.35 & 1.06 & 0.44 & 1.62 & 0.18 & 0.64 & 0.05 \\
(year 4) & & & & & & & & & \\
Rhizomes without periderm, September 22, & 0.13 & - & - & - & 0.75 & 1.53 & 0.61 & 2.45 & 0.05 & 0.15 \\
2020 (year 4) & & & & & & & & - \\
\hline
\end{tabular}

1-Gallic acid (1.8 min), 2-unidentified compound (2.9 min), 3-unidentified compound (6.5 min), 4-unidentified compound (8.5 min), 5-rosarin (10.7 $\mathrm{min}), \mathbf{6}$-rosavin (12.5 min), 7-rosin (13.5 min), 8-cinnamyl alcohol (24.3 min), 9-rhodiosin (39.9 min), 10-rhodionin (40.5 min), 11-kaempferol (47.1 min).

Table 3. ROS, CA and derived variables ROS/CA ratio and phenylpropanoids in water-ethanol extracts from rhizomes and roots of 2- to 4-year-old $R$. rosea cultivated in CSBG (Novosibirsk, Russia)

\begin{tabular}{l|c|c|c|c|c|c|c|c}
\hline \multirow{2}{*}{$\begin{array}{c}\text { Year of } \\
\text { cultivation }\end{array}$} & \multicolumn{2}{|c|}{ ROS, \% } & \multicolumn{2}{c|}{ CA, \% } & \multicolumn{2}{c|}{ ROS-CA ratio $x: 1$} & \multicolumn{2}{c}{ PP, \% } \\
\cline { 2 - 8 } & Rhizome & Root & Rhizome & Root & Rhizome & Root & Rhizome & Root \\
\hline Year 2 & 2.69 & 0.47 & 2.77 & 0.27 & $0.97: 1$ & $1.74: 1$ & 5.46 & 0.74 \\
Year 3 & 2.01 & 0.15 & 2.52 & 0.20 & $0.80: 1$ & $0.75: 1$ & 4.53 & 0.35 \\
Year 4 & 4.71 & 0.80 & 3.39 & 0.78 & $1.39: 1$ & $1.02: 1$ & 8.1 & 1.58 \\
\hline
\end{tabular}

PP, phenylpropanoids.

The ROS-CA ratio changed significantly by the 4th year of cultivation: this indicator increased in rhizome and decreased in roots (Fig. 4). It should be noted that the 2-year-old plants were grown in containers. Comparison of the data on yield and biosynthesis of ROS indicates a direct correlation between these parameters.

The phenylpropanoid profile, i.e. the relative ratio between the three rosavins and CA (proportions of rosarin-rosavin-rosin-CA), varied depending on the plant age (Fig. 4). This ratio varied as follows: $0.2-$ $0.3: 0.4-0.8: 0.1-0.3: 1$ for rhizome, and $0.2-0.3$ : $0.3-0.9: 0.3-0.4: 1$ for roots. Among ROS, the most significant changes in rhizome and roots were observed for rosavin, and CA prevailed in all the samples studied. A detailed analysis of ROS showed that rosavin is the prevailing component in all the samples, except for roots of the 2-year-old plants.

The rhizome and periderm of the 4-year-old plants were analyzed separately. The content of ROS and CA was high in the rhizome peridem, and the ratio was similar to that in the rhizome (Fig. 5). It should be noted that some phenolic compounds were not found in the rhizome, but were observed in the periderm: $2(0.05 \%)$, $3(0.04 \%)$, and 11, kaempferol (0.05\%) (Table 2).

\section{DISCUSSION}

The data on the content of glycosides in $R$. rosea are numerous and contradictory (Kim, 1999; Kurkin et al., 2013; Peschel et al., 2015). Researchers have not yet come to a consensus about the localization and activity of specialized biosyntheses, the nature of seasonal changes in the content of glycosides, and the variability of the accumulation of these substances in wild and cultivated plants. We have conducted detailed comparative studies of the content and localization of phenolic compounds in the cultivated plants of $R$. rosea from Altai Mountains. A total of 11 phenolic compounds were identified, including gallic acid, rosarin, rosavin, rosin, cinnamyl alcohol, rhodiosin, rhodionin, and kaempferol. A unified determination method employed in the studies revealed the presence of phenylpropanoids only in roots and rhizome. Histochemical methods confirmed the presence of phenolic compounds in the parenchyma and vascular tis- 

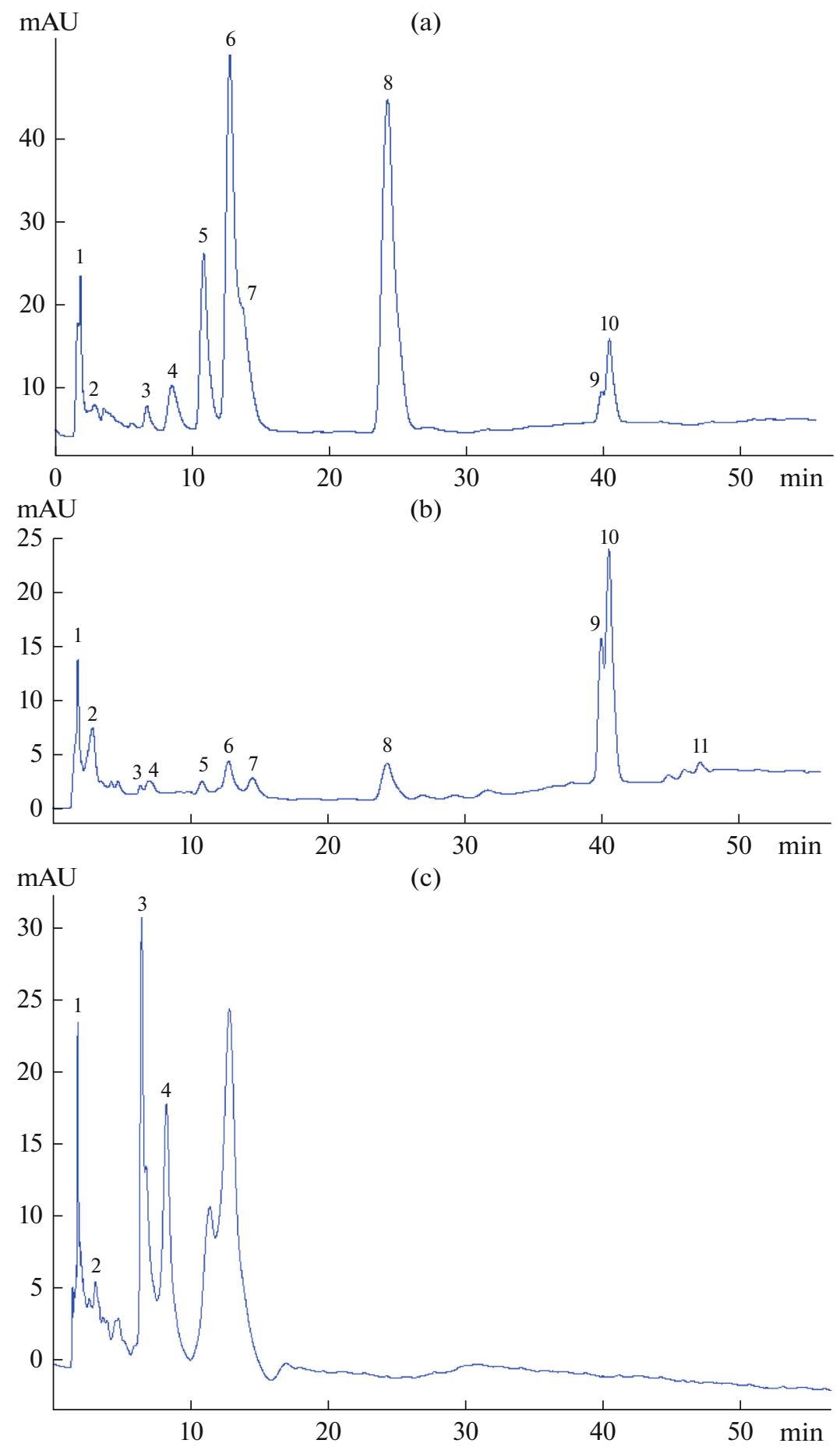

Fig. 3. Chromatogram of a water-ethanol extract of the rhizomes (year 4) (a), roots (year 2) (b) and herb (year 4) (c) of $R$. rosea. The abscissa is the retention time, $t$, min; ordinate is absorbance, mAU. The numbers in the chromatogram indicate the numbers of compounds corresponding to the numbers of compounds in Table 2.

sues of $R$. rosea. Phenylpropenoids were not found in the aerial part (stems, leaves).

The minimum ROS content is $0.3 \%$ according to the USP (2015) and 1\% according to the Gosudarst- vennaya farmakopeya..., 2015 (2015). The ROS content in the samples studied $(2.01-4.71 \%$ for dry rhizomes) corresponds to these standards. The recently reported ROS range is $0.2-3.7 \%$ DW for rhizome/root mixtures (or other parts of the plant), 0.4- 

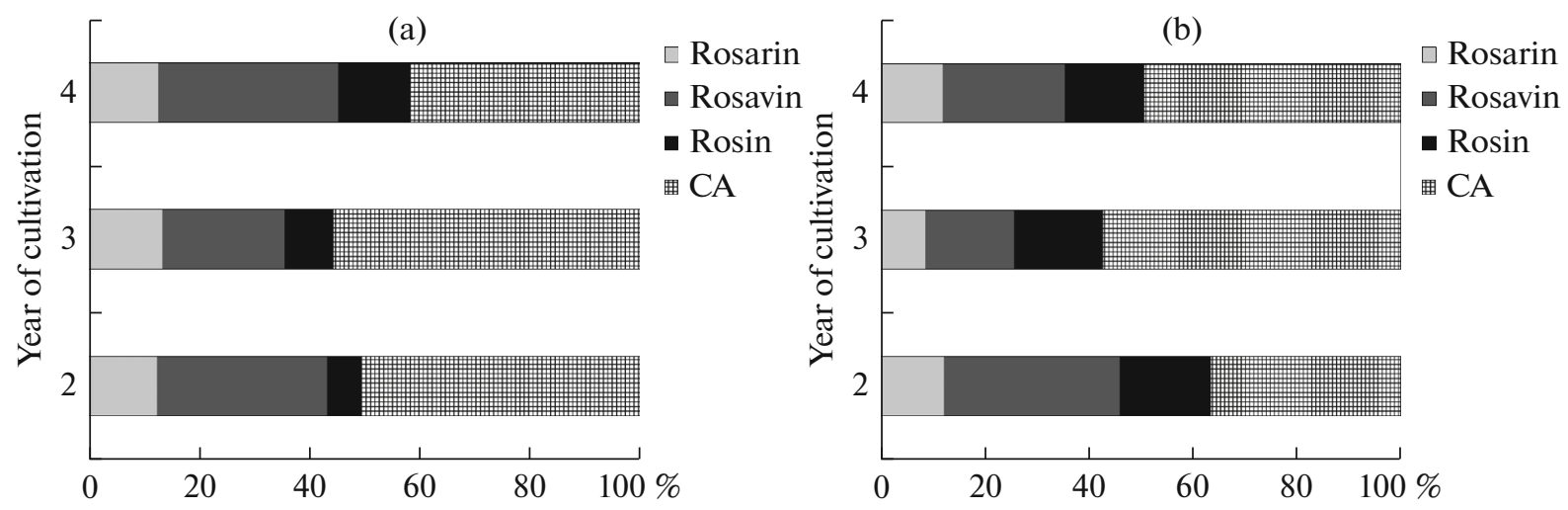

Fig. 4. Relative phenylpropenoid profile (\%) of rhizome (a) and root (b) of $R$. rosea cultivated in CSBG (Novosibirsk, Russia).

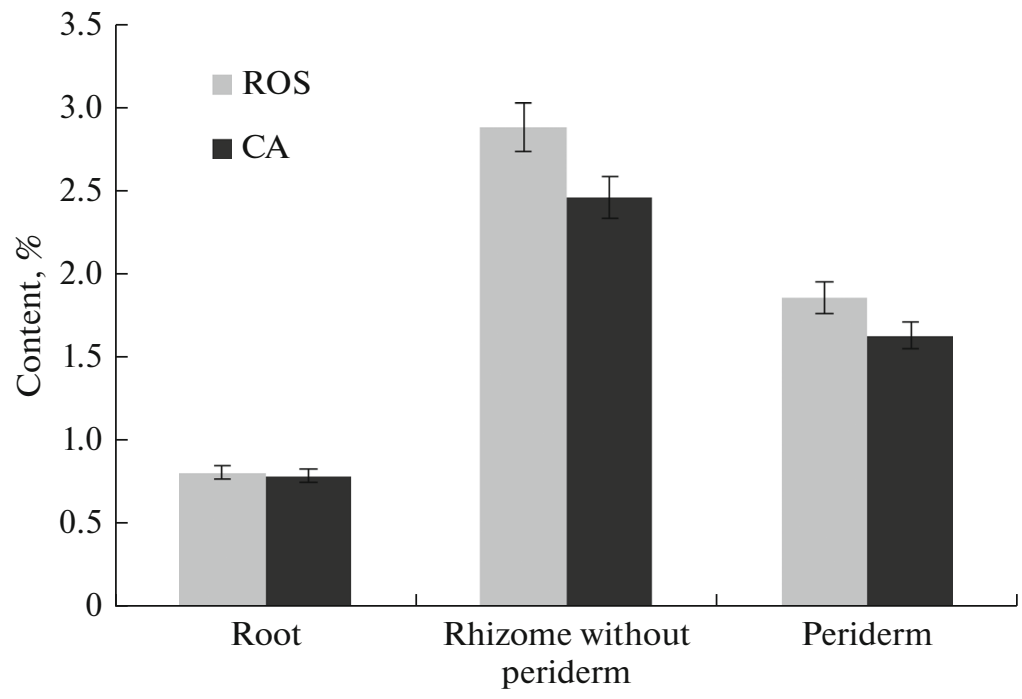

Fig. 5. ROS and CA in roots, rhizomes without periderm and periderm of rhizomes of $R$. rosea (year 4) cultivated in CSBG (Novosibirsk, Russia). Data are presented as mean values with confidence intervals $(p \leq 0.05)$.

$5.5 \%$ for rhizomes, and $0.5-3.3 \%$ for roots (Peschel et al., 2015). CA is not considered in the quality control of $R$. rosea, although this compound is usually found in samples. In the samples studied, it accounts for up to $58 \%$ of the total phenylpropanoid content. In studies by Peschel et al. (2015), CA accounts for about $20 \%$ of the phenylpropanoid content in $R$. rosea samples.

According to our data, the phenylpropanoid content increases with plant age. In all the studied samples, phenylpropanoid content in rhizomes exceeded that in roots. The highest phenylpropanoid content was recorded in rhizomes of the 4-year-old plants: $1.02 \%$ rosarian, $2.64 \%$ rosavin, $1.05 \%$ rosin, $3.39 \%$ CA. It was found that the rosavin content in rhizomes of the 4-year-old $R$. rosea plants introduced into the foreststeppe zone of Western Siberia (2.64\%) corresponds to its content in wild $R$. rosea plants confined to Altai Mountains (2.5\% according to Kurkin, 1985). It was also shown that the ROS-CA ratio changes with plant age: a shift towards ROS was observed in rhizome and that towards CA was found in roots. In all the studied samples, CA prevailed among phenylpropanoid and rosavin prevailed among ROS. According to other studies, the main component of the phenylpropanoid profile in both wild and cultivated $R$. rosea is rosavin (Wiedenfeld et al., 2007; Altantsetseg et al., 2007; Peschel et al., 2015). At the same time, Wiedenfeld et al. (2007) reported that one of the $R$. rosea plants collected in Mongolia (2002) did not contain rosavin and CA, which was attributed to poor climatic conditions.

It was shown that in the conditions of plant introduction in the forest-steppe zone of Western Siberia, an increase in the biomass of underground parts of $R$. rosea with plant age is mainly due to rhizome (rhizom-root ratio is $1: 0.58$ ). The FW of rhizomes and roots of the 4-year-old plants was $117.7 \mathrm{~g}$, which is approximately 2 -fold greater than that of $R$. rosea growing in Altai Mountains. According to Kim (1999), 
$R$. rosea exhibited high biological productivity in the introduction conditions. In some experiments, the biomass of the introduced 4-5-year-old plants of $R$. rosea exceeded the biomass of wild plants 10 fold. We found that the rhizome particulation occurs in 4year-old plants. According to Zaprometov (1993), the localization of glycosides in the underground parts of $R$. rosea is probably associated with their participation in the formation of lignin and suberin. CA and its oxidation products are involved in the creation of a threedimensional structure of lignin. This is important for vegetative propagation of $R$. rosea through rhizome breaking or particulating, which is often observed in wild (Frolov and Poletaeva, 1998).

Histochemical methods are fast and cheap and can be used to identify bioactive classes of compounds in tissues and cell compartments (Matias et al. 2016). Interpretation of histochemical results allows comparison of plant parts, species or materials from different habitats or seasons (Coelho et al., 2012; Adams et al., 2013). Our histochemical studies confirm the presence of phenolic compounds in rhizomes and roots of $R$. rosea, which are localized in parenchymal and vascular tissues. We additionally evaluated the content of phenolic compounds in the rhizome periderm. The content of ROS and CA in the rhizome periderm was high, and the ROS-CA ratio was similar to that in the rhizome. Histochemical studies revealed the presence of phenolic compounds only in the cells of the parenchyma adjacent to the periderm. For periderm cells, a ferric chloride test for phenolic compounds was negative. The presence of phenylpropanoids in the analyzed periderm is probably associated with the partial presence of rhizome parenchyma cells in the studied samples.

\section{CONCLUSION}

HPLC was employed to isolate 11 phenolic compounds, including gallic acid, rosarin, rosavin, rosin, cinnamyl alcohol, rhodiosin, rhodionin, and kaempferol. The highest PP content was found in rhizomes of the 4-year-old $R$. rosea plants: $1.02 \%$ rosarin, $2.64 \%$ rosavin, $1.05 \%$ rosin, $3.39 \% \mathrm{CA}$. Analysis of the phenylpropanoid profile showed that cinnamyl alcohol prevailed in all the studied samples (up to 58\%). Histochemical studies confirm the presence of phenolic compounds in $R$. rosea roots and rhizomes, which are localized in the parenchymal and vascular tissues. It was shown that the total rhizome biomass exceeded that of the root, and after 4 years of cultivation, it exhibited a 2-fold increase in dry weight. The study has shown high biosynthetic potential and biological productivity of $R$. rosea plants of Altai Mountains ecotype upon introduction in the forest-steppe zone of Western Siberia.

\section{ACKNOWLEDGMENTS}

To prepare the publication, materials of the bioresource scientific collection of the Central Siberian Botanical Garden of the SB RAS "Collection of living plants indoors and outdoors", USU_440534 were used.

\section{FUNDING}

The research was funded by the Russian Foundation for Basic Research and Novosibirsk region, project no. 20-44540005.

\section{COMPLIANCE WITH ETHICAL STANDARDS}

This article does not contain any studies involving animals performed by any of the authors.

\section{CONFLICT OF INTEREST}

The authors declare that they have no conflicts of interest.

\section{REFERENCES}

Adams, S.J., Kuruvilla, G.R., Krishnamurthy, K.V., Nagarajan, M., and Venkatasubramanian, P., Pharmacognostic and phytochemical studies on Ayurvedic drugs Ativisha and Musta, Rev. Bras. Farmacogn., 2013, vol. 23, pp. 398-409.

https://doi.org/10.1590/S0102-695X2013005000040

Altantsetseg, K., Przybył, J.L., Zenon, W., and Geszprych, A., Content of biologically active compounds in roseroot (Rhodiola sp.) raw material of different derivation, Herba Pol., 2007, vol. 53, pp. 20-26.

Banaev, E.V., On the effect of climate on the morphological structure of Alnus hirsute (Betulaceae), Russ. J. Ecol., 2009, vol. 40, no. 1, pp. 18-23.

https://doi.org/10.1134/S1067413609010032

Brinckmann, J.A., Cunningham, A.B., and Harter, D.E.V., Running out of time to smell the roseroots: Reviewing threats and trade in wild Rhodiola rosea L., J. Ethnopharmacol., 2021, vol. 269, 113710. https://doi.org/10.1016/j.jep.2020.113710

Coelho, V.P.M., Leite, J.P.V., Nunes, L.G., and Ventrella, M.C., Anatomy, histochemistry and phytochemical profile of leaf and stem bark of Bathysa cuspidate ( $\mathrm{Ru}-$ biaceae), Aust. J. Bot., 2012, vol. 60, pp. 49-60. https://doi.org/10.1071/BT11315

Erst, A.A. and Yakubov, V.V., Regenerative in vitro capacity of rare species Rhodiola rosea L. from various habitats, Contemp. Probl. Ecol., 2019, vol. 12, pp. 368-376. https://doi.org/10.1134/S1995425519040036

Erst, A.A., Erst, A.S., and Shmakov, A.I., In vitro propagation of rare species Rhodiola rosea from Altai Mountains, Turczaninowia, 2018, vol. 21, no. 4, pp. 78-86. https://doi.org/10.14258/turczaninowia.21.4.9

European Commission Cosmetic ingredient database, European commission directorate general for internal market, industry, entrepreneurship and SMEs, Brussels, 2020. https://ec.europa.eu/growth/sectors/cosmetics/ cosing_en. 
Frolov, Yu.M. and Poletaeva, I.I., Rodiola rozovaya na Evropeiskom severo-vostoke (Rhodiola rosea in the European Northeast), Yekaterinburg, 1998.

Gosudarstvennaya farmakopeya Rossiiskoi Federatsii, XIII izdaniya. FS.2.5.0036.15 Rodioly rozovoi kornevishcha $i$ korni (Russia State Pharmacopoeia, 13 Edition. FS.2.5.0036.15 Rhodiola rosea Rhizomes and Roots), Moscow, 2015.

Ishmuratova, M.M., Clonal micropropagation of Rhodiola rosea $\mathrm{L}$. and $R$. iremelica Boriss. in vitro, Rastit. Resur., 1998, vol. 34, pp.12-23.

Johansen, D.A., Plant Microtechnique, New York: McGraw-Hill, 1940.

Kedzia, B., Furmanowa, M., Krajewska-Patan, A., Holderna-Kedzia, E., Mscisz, A., Wojcik, J., Buchwald, W., and Mrozikiewicz, P.M., Studies on the toxicity, adaptogenic and antimicrobial activity of extracts obtained from the underground parts of selected species of Rhodiola L., Herba Pol., 2006, vol. 52, no.4, pp. 117-132.

Kim, E.F., The experience of growing Rhodiola rosea in the low mountains of Altai, Rastit. Resur., 1976, vol. 12, no. 4, pp. 583-590.

Kim, E.F., Rhodiola rosea (golden root) (Crassulaceae) and the biological basis of its introduction into culture, Doctoral (Biol.) Dissertation, Novosibirsk, 1999.

Kurkin, V.A., Phenylpropanoids as the biologically active compounds of the medicinal plants and phytopharmaceuticals, Adv. Biol. Chem., 2013, vol. 3, pp. 26-28. https://doi.org/10.4236/abc.2013.31004

Lamadrid, P., Williams, D.K., Kilpatrick, M.W., Bickford, P.C., and Sanberg, C., The impact of dietary supplement NT-020 with Rhodiola rosea on energy, fatigue, and perceived exertion, Funct., Food. Health Dis., 2019, vol. 9 , no. 11, pp. $706-718$. https://doi.org/10.31989/ffhd.v9i11.656

Matias, L.J., Mercadante-Simões, M.O., Royo, V.A., Ribeiro, L.M., Santos, A.C., and Fonseca, J.M.S., Structure and histochemistry of medicinal species of Solanum, Rev. Bras. Farmacogn., 2016, vol. 26, pp. 147-160. https://doi.org/10.1016/j.bjp.2015.11.002

Panossian, A. and Brendler, T., The role of adaptogens in prophylaxis and treatment of viral respiratory infec- tions, Pharmaceuticals, 2020, vol. 13, pp. 236-267. https://doi.org/10.3390/ph13090236

Panossian, A., Wikman, G., and Sarris J., Rosenroot (Rhodiola rosea): Traditional use, chemical composition, pharmacology and clinical efficacy, Phytomedicine, 2010. vol. 17, no. 7, pp. 481-493.

Peschel, W., Kump, A., Horváth, A., and Csupor, D., Age and harvest season affect the phenylpropenoid content in cultivated European Rhodiola rosea L., Ind. Crops Prod., 2016, vol. 83, pp. 787-802.

https://doi.org/10.1016/j.indcrop.2015.10.037

Rastitel'noe mnogoobrazie Tsentral'nogo sibirskogo botanicheskogo sada SO RAN (Plant Diversity of the Central Siberian Botanical Garden, Siberian Branch, Russian Academy of Sciences), Koropachinskii, I.Yu. and Banaev, E.V., Eds., Novosibirsk: Geo, 2014.

Tasheva, K. and Kosturkova, G., The role of biotechnology for conservation and biologically active substances production of Rhodiola rosea: Endangered medicinal species, Sci. World J., 2012, vol. 2012, 274942. https://doi.org/10.1100/2012/274942

USP Herbal Medicines Compendium, Monograph: Rhodiola Rosea Root and Rhizome Powder, Rockville, MD: US Pharmacopeial Convention, 2015.

Wiedenfeld, H., Dumaa, M., Malinowski, M., Furmanowa, M., and Narantuya, S., Phytochemical and analytical studies of extracts from Rhodiola rosea and Rhodiola quadrifida, Pharmazie, 2007, vol. 62, pp. 308-311. https://doi.org/10.1691/ph.2007.4.6664

Wiesner, J., Note on the behavior of phloroglucin and some related bodies to the lignified cell membrane, Sess. Rep. Imper. Acad. Sci., Math.-Nat. Classe, 1878, vol. 77, pp. 60-66.

Zakhozhii, I.G., Physiological and biochemical bases of accumulation of products of secondary metabolism salidroside and rosavin in Rhodiola rosea L., Cand. Sci. (Biol.) Dissertation, St. Petersburg, 2006.

Zaprometov, M.N., Fenol'nye soedineniya: rasprostranenie, metabolizm $i$ funktsii $v$ rasteniyakh (Phenolic Compounds: Distribution, Metabolism, and Function in Plants), Moscow: Nauka, 1993. 